\title{
Integrative taxonomy of two thrush complexes (Aves: Turdidae) reveals introgression across sister species
}

\author{
BOYANG AN ${ }^{1}$, DANYANG YIN ${ }^{1}$, SONGLIN HUANG ${ }^{2}$, TARIQ AHMAD ${ }^{1}$, and Li Bo ${ }^{1}$ \\ ${ }^{1}$ Northeast Forestry University \\ ${ }^{2}$ Chinese Academy of Forestry
}

November 24, 2021

\begin{abstract}
The classification of some Turdus species, such as the Naumann's and dusky thrush complexes and the red-throated and black-throated thrush complexes, is controversial. Herein, we used molecular data (mitochondrial genes and microsatellite loci) and morphological characters to review the taxonomy of these thrush complexes and analyze the genetic differentiation between them. Our phylogenetic analysis based on mitochondrial genes indicated that all haplotypes could be divided into two reciprocally monophyletic sister clades corresponding to these two thrush complexes. The same results were revealed by coalescence-based species delimitation. Therefore, these two thrush complexes should be divided into two separate species (T. naumanni and T. ruficollis) and include two subspecies per species according to combined characters from morphological analyses and multilocus approaches. The above classifications were also supported by an analysis of genetic differentiation between T. naumanni and T. ruficollis and within each species. Moreover, there was significant mixing between these two thrush species in the neighbor-joining (NJ) tree and the cluster analysis of microsatellite loci. This led to a pattern of nuclearmitochondrial discordance between the two species. This could be the result of extensive nuclear introgression between these two sister species. We also provide a potential explanation for the mechanism of gene introgression and nuclear-mitochondrial discordance between the two bird species.
\end{abstract}

\section{Introduction}

Introgression mediates gene flow across the classification boundary between two species since hybridization or backcrossing occurs between these species due to incomplete reproductive isolation (Bolnick and Near, 2005; Mao et al., 2013). In animals, introgression can impact on species integrity in evolutionary processes (Petit and Excoffier, 2009). For example, when parental species continue to cross and produce viable, fertile progeny, and when the filial generations occupy ecological niches that cannot be occupied by the parental species, they eventually evolve into a new species through hybridization (Nolte and Tautz, 2010). Thus, it is very important to explore hybridization and introgression between species, which can explain which species succeeded and which become extinct (Pfennig, 2021).

Introgression occurs more frequently among birds than in mammal species (Grant and Grant, 1992; Mallet, 2005). It has been reported that more than $9 \%$ of birds have undergone introgression, and the proportion of introgression among birds worldwide may be higher (Grant and Grant, 1992; Randler, 2002). These birds include Larus hyperboreus and L. argentatus in Iceland (Vigfusdottir et al., 2008),Aegithalos bonvaloti and A. fuliginosus in southwestern China (Wang et al., 2014), Ammodramus caudacutus and A. nelsoni on the northeastern coast of the United States (Walsh et al., 2016), and Strix varia and S. occidentalis in western North America (Hanna et al., 2018). Recently, some studies have shown that when reconstructing phylogenetic relationships among related species, introgression might exacerbate nuclear-mitochondrial discordance (Haines et al., 2017; Kinoshita et al., 2019; Lu et al., 2001; Walsh et al., 2016). There are several possible hypotheses to explain these phenomena among birds, such as sex bias (Dai et al., 2013; Toews and Brelsford, 
2012), distribution changes (Seixas et al., 2018), and simple stochastic variation in coalescence times across loci (Phuong et al., 2017; Rosenberg, 2003).

Turdidae includes approximately 340 species, which are distributed worldwide. Among these species, 65 are in Turdus (Monroe B.L., 1993). The classification of several Turdus species, such as the Naumann's and dusky thrush complexes and the red-throated and black-throated thrush complexes, is controversial (Kratter, 2014; Sibley C.G., 1990). One opinion is that they are two species and four subspecies, i.e., T. naumanni naumanni and T. naumanni eunomus and T. ruficollis ruficollis and T. ruficollis atrogulari $\mathrm{s}$ (Zheng, 1994). This is in line with the results of phylogenetic analysis using mitochondrial genes and nuclear introns (Nylander et al., 2008). On the other hand, based on clear morphological differences, they have been identified as four separate species, i.e.,T. naumanni, T. eunomus, T. ruficollis and T. atrogularis (Brazil, 2009; Sangster et al., 2007; Zheng, 2017). However, the latter view has been challenged by the observation of intermediate specimens between Naumann's and dusky thrushes (Dong et al., 2018) and red-throated and black-throated thrushes (Brazil, 2009). Therefore, an integrative taxonomy of these two thrush complexes is still necessary.

In the present study, we used morphological characteristics, including quantitative and qualitative features, to identify these two thrush complexes and define intermediate specimens. Using mitochondrial genes and microsatellite loci, we then analyzed the genetic structure of these two thrush complexes. It was revealed for the first time that they are sister species with extensive nuclear introgression.

\section{Material and methods}

\subsection{Bird sampling and identification}

One hundred thirty-two individual thrushes were provided by the sample library of the State Forestry and Grassland Administration Detecting Center of Wildlife Resources (Harbin, China) and were legally collected and well preserved for use in enforcement in cases involving forensic analysis (Table 1). Using 16 morphological features (Table 2, (Brazil, 2009; Chang, 1995), we identified these thrush species, including Naumann's thrush $(N=61)$, the dusky thrush $(N=24)$, the red-throated thrush $(N=32)$, and the blackthroated thrush $(N=3)$ (Table 1$)$. Individuals with multiple morphological characteristics matching those of different species were considered intermediate specimens $(N=24)$. Muscle samples were cut from the birds and stored at $-20^{\circ} \mathrm{C}$ for subsequent molecular experiments. Feather samples from 14 individuals (two or three contour feathers per bird) were also included and were plucked from the back or the breast of dusky and pale thrushes (Table 1). Bird banding technicians sampled the feathers during the autumn migration season in mid-eastern and southeastern China in 2017 according to the Operational Instructions of Bird Handling. Feather samples were naturally dried and preserved in paper envelopes at $4^{\circ} \mathrm{C}$.

\subsection{DNA extraction and PCR amplification}

Muscle samples or the calamus of the contour feathers were excised into a $1.5 \mathrm{ml}$ Eppendorf tube and refreshed in TNE buffer (10 mM Tris-HCl (pH 8.0), $150 \mathrm{mM} \mathrm{NaCl}, 2 \mathrm{mM}$ EDTA, 1\% SDS). Total genomic DNA was extracted and purified using an AxyPrep Multisource Genomic DNA Miniprep Kit (AxyGen, Hangzhou) according to the manufacturer's instructions. All DNA extracts were quantified using a Nanodrop 2000c (Thermo Scientific, USA) and diluted to $50 \mathrm{ng} / \mu \mathrm{L}$.

We amplified two mitochondrial genes (COI and ND2). The amplification profile of COI was standardized as follows: $25.0 \mu \mathrm{l}$ of 2x EasyTaq PCR SuperMix (Transgen Biotech, Beijing), $18.0 \mu \mathrm{l}$ of deionized water, $1.0 \mu \mathrm{l}$ $(10 \mathrm{pmol} / \mu \mathrm{l})$ of each primer (BirdF1 and BirdR1, (Kerr et al., 2009)) and $5.0 \mu \mathrm{l}(20 \mathrm{ng})$ of genomic DNA. The PCR conditions were as follows: initial denaturation at $94^{\circ} \mathrm{C}$ for $30 \mathrm{~s} ; 30$ cycles of $94^{\circ} \mathrm{C}$ for $30 \mathrm{~s}, 54^{\circ} \mathrm{C}$ for $30 \mathrm{~s}$ and $72^{\circ} \mathrm{C}$ for $1 \mathrm{~min}$; and a final extension at $72^{\circ} \mathrm{C}$ for $5 \mathrm{~min}$. The amplification profile of ND2 was standardized as follows: $0.5 \mu \mathrm{l}$ of LA Taq DNA polymerase (TaKaRa, Dalian), $5.0 \mu \mathrm{l}$ of dNTPs, $5.0 \mu \mathrm{l}$ of LA Taq buffer, $32.5 \mu \mathrm{l}$ of deionized water, $1.0 \mu \mathrm{l}(10 \mathrm{pmol} / \mu \mathrm{l})$ of each primer (L5216 and H6313, (Sorenson et al., 1999)) and $5.0 \mu \mathrm{l}(20 \mathrm{ng})$ of genomic DNA. The PCR conditions were as follows: initial denaturation at $94^{\circ} \mathrm{C}$ for $1 \mathrm{~min}$; 30 cycles of $94^{\circ} \mathrm{C}$ for $1 \mathrm{~min}, 54^{\circ} \mathrm{C}$ for $45 \mathrm{~s}$ and $72^{\circ} \mathrm{C}$ for $1.5 \mathrm{~min}$; and a final extension at $72^{\circ} \mathrm{C}$ for 5 min. The 
amplified products were separated on a $1 \%$ agarose gel. DNA fragments from the same individual bands were recovered and purified using an AxyPrep DNA Gel Extraction Kit (AxyGen, Hangzhou) according to the manufacturer's instructions. The recovered PCR products were sequenced directly using Sanger sequencing on an ABI 3730 DNA Analyzer following the primer-walking strategy (performed by BGI, Beijing).

We characterized 13 microsatellite loci for the targeted thrush species; the loci were identified among 38 loci originally isolated from the related species Turdus merula (Simeoni et al., 2009). The 5' end of each forward primer was connected to a fluorescent dye-labeled M13 (Guo and Milewicz, 2003; Schuelke, 2000), and the fluorescent label was FAM or JOE. The amplification profile of the microsatellite loci was standardized as follows: $5.0 \mu \mathrm{l}$ of Ex Taq DNA polymerase (TaKaRa, Dalian), $3.5 \mu \mathrm{l}$ of $\mathrm{H}_{2} \mathrm{O}, 0.2 \mu \mathrm{l}$ of BSA, $0.1 \mu \mathrm{l}(10 \mathrm{pmol} / \mu \mathrm{l})$ of each primer, $0.1 \mu \mathrm{l}(10 \mathrm{pmol} / \mu \mathrm{l})$ of M13 and $3.5 \mu \mathrm{l}(20 \mathrm{ng})$ of genomic DNA. The PCR conditions were as follows: initial denaturation at $94^{\circ} \mathrm{C}$ for $3 \mathrm{~min} ; 20$ cycles of $94^{\circ} \mathrm{C}$ for $30 \mathrm{~s}$, the annealing temperature for 30 $\mathrm{s}$ and $72^{\circ} \mathrm{C}$ for $45 \mathrm{~s} ; 15$ cycles of $94^{\circ} \mathrm{C}$ for $30 \mathrm{~s}, 60^{\circ} \mathrm{C}$ for $30 \mathrm{~s}$ and $72^{\circ} \mathrm{C}$ for $45 \mathrm{~s}$; and a final extension at $72^{\circ} \mathrm{C}$ for $10 \mathrm{~min}$. Amplicons were sized by a service provider (Shenggong BioTech) using capillary electrophoresis with an ABI 3730xl DNA analyzer. Alleles were scored using GeneMapper software version 4.0 (Applied Biosystems Inc.). The names, sequences and annealing temperatures of these primers are shown in Table S1.

\subsection{Molecular characterization}

Sequences from overlapping fragments were assembled with contiguous fragments using SeqMan software (DNAStar, USA). Sequences of COI and ND2 were aligned using the Clustal W algorithm in MEGA version 5.0 (Tamura et al., 2011). Due to the different sequence lengths, we cut the sequences according to the greatest common divisor. The numbers of variable sites, singleton variable sites, and parsimony informative sites were determined using MEGA version 5.0 (Tamura et al., 2011).

The genetic diversity parameters of the microsatellite variation, including the number of alleles (Na), the number of effective alleles ( $\mathrm{Ne}$ ), the expected heterozygosity (He) and the observed heterozygosity (Ho), were summarized using POPGENE version 1.32. The polymorphism information content (PIC) was calculated using Cervus 3.0.3. (Kalinowski et al., 2007). Deviations from Hardy-Weinberg equilibrium (HWE) locus were tested for each locus using GENEPOP (Raymond and Rousset, 1995).

\subsection{Genetic structure analysis}

Phylogenetic analyses based on the COI and ND2 genes were conducted using the Bayesian inference (BI) and maximum likelihood (ML) methods, and four thrush species (T. chrysolaus : DQ911070 and GQ482817;T. chiguanco : AY329443 and FJ028500; T. leucomelas : DQ911086 and KT236270 and T. pallidus : obtained in this study) were used as outgroups in the analyses. Substitution models for data sets were selected using MrModeltest 2.3 according to Akaike's information criterion. BI analysis was performed using the Markov chain Monte Carlo technique (MCMC) in MrBayes version 3.1.2 (Ronquist and Huelsenbeck, 2003). Two sets of four chains were allowed to run simultaneously for 10 million generations, and each set was sampled every 1000 generations. A consensus tree was then calculated after omitting the first $25 \%$ of trees as burn-in. The ML analysis was performed using Iqtree-omp version 1.5.5 (Nguyen et al., 2015), and 1000 bootstraps were used to estimate the node reliability. The inferred phylogenetic trees were summarized as maximum clade credibility trees using TreeAnnotator 2.4.3 (Rambaut and Drummond, 2016) and edited in FigTree 1.4.2. (Rambaut, 2014). A bootstrap (BS) value of $70 \%$ or greater was considered strong support, and posterior probabilities (PPs) of $95 \%$ or greater were considered significant support (Leache and Reeder, 2002).

Uncorrected pairwise p-distances based exclusively on the sequences of ND2 were calculated, both within and between lineages, as defined by the recovered phylogenies, using MEGA 5.0 software (Tamura et al., 2011). To detect signatures of population structure, pairwise $F_{s t}$ values (Weir and Cockerham, 1984) were calculated among species using Arlequin version 3.5 (Excoffier and Lischer, 2010). When analyzing microsatellite data, Arlequin was also used. The gene flow index $\left(N_{e} m\right)$ was calculated by using the formula $F_{\text {st }}=1 /\left(4 N_{e} m+1\right)$.

Based on the microsatellite data, we used the Bayesian clustering approach in STRUCTURE 2.2 (Pritchard et al., 2000) to identify the most likely number of clusters (K) and assign individuals to these clusters. We 
performed ten runs for each hypothesized number of subpopulations. Runs of 1,000,000 permutations after 100,000 MCMC burn-ins were conducted from $\mathrm{K}=1$ to 5 using the admixture model, with allele frequencies assumed to be correlated. A neighbor-joining (NJ) tree based on shared allele distances (SADs) between individuals was constructed using Population 1.2.32 (Kalinowski, 2002; Takezaki and Nei, 1996)

\subsection{Morphometric analysis and coalescence-based species delimitation (BPEP)}

Some individuals were excluded from the morphometric analysis because of incomplete morphological features, such as missing heads or partial feathers. A total of 77 individuals, including Naumann's thrush $(N$ $=33)$, the dusky thrush $(N=8)$, the red-throated thrush $(N=33)$, and the black-throated thrush $(N=3)$, were used in the morphometric analysis. Five morphological features, tail length, wing length (maximum chord), toe length, claw length and instep length, were measured using an electronic vernier caliper (with an accuracy of 0.001). Principal component analysis (PCA) of morphometric data was performed using SPSS.

The interspecific limits between the sampled Turdus taxa were tested using Bayesian Phylogenetics and Phylogeography (BP\&P; version 2.2). BP\&P software uses a Bayesian approach to generate probabilities of speciation between closely related taxa, using multilocus sequence data (Rannala and Yang, 2003; Yang and Rannala, 2010). We used the ML/BI tree as the guide tree to run BP\&P, and the selected model specified species delimitation as 1: rjMCMC and species tree 0: species tree fixed. In this model, two different algorithms (0: algorithm0 and 1: algorithm1) are used to combine different prior probability distributions of species divergence times $\tau$ and population size parameters $\vartheta\left(\vartheta=4 N_{\epsilon} \mu\right)$, where Ne is the effective population size and $\mu$ is the substitution rate per site per generation (Cerqueira et al., 2016).

The two models use three combinations: the first is a large population size and long divergence time, $\vartheta^{\sim} \mathrm{G}$ $(1,10) \tau^{\sim} \mathrm{G}(1,10)$; the second is a large population size and short divergence time, $\vartheta^{\sim} \mathrm{G}(1,10) \tau^{\sim} \mathrm{G}(2$, $2000)$; and the third is a small population size and short divergence time, $\vartheta^{\sim} \mathrm{G}(2,2000) \tau^{\sim} \mathrm{G}(2,2000)$. Markov chains were run for 100,000 generations and sampled every five generations. The first 20,000 runs were discarded as burn-in.

\section{Results}

\subsection{Molecular characters}

The sequencing of partial ND2 and COI genes defined a total of 62 and 39 haplotypes, respectively, among the four thrush species. We identified 88 variable sites in the 987-bp ND2 gene (no. 19-1006), of which 41 sites were parsimony informative. There were 44 mutation sites among the COI gene fragments (666 bp, no. 70-736), including 21 parsimony-informative sites. The aligned length of the ND2+COI sequences was 1,653 bp. All the ND2 and COI sequences, except those from the intermediate specimens, were deposited in GenBank under accession nos. MT977415-MT977542.

We examined the genetic characteristics of 13 microsatellite loci in all individuals (Table 3). A total of 129 alleles were detected, of which PAT MP 2-43 had the most alleles $(\mathrm{Na}=24)$ and TG02-078 had the fewest alleles $(\mathrm{Na}=3)$. The most variable loci were PAT MP 2-43 and Til-04 (He=0.902 and 0.854, respectively), while the least variable loci were TG02-078, TG07-022 and TG03-002 (He=0.190, 0.197 and 0.206, respectively). The average number of alleles at the 13 loci was 9.4615 , and the average number of effective alleles was 3.9235, indicating that the 13 loci represented unevenly distributed alleles in the populations of these birds. Based on Fisher's method, only Tmer-03, PAT MP 2-43, TG02-078, TG07-022, TG11-011 and TG12015 were in Hardy-Weinberg equilibrium $(\mathrm{P}>0.05)$. Therefore, for the sake of conservatism, when analyzing population genetic differentiation based on microsatellites, in this study, we only used these 6 microsatellite loci.

\subsection{Genetic structure}

We reconstructed the phylogenetic relationships between the Naumann's and dusky thrush complexes and the red-throated and black-throated thrush complexes based on haplotype sequences of the partial ND2 and COI genes (Fig. 1). The BI and ML trees of the dataset had similar topologies, and only the nodes 
of two thrush complexes were significantly supported by the posterior probability (PP> 95\%) and the bootstrap value (BS> 75). The rest of the nodes within the Naumann's and dusky thrush complexes or the red-throated and black-throated thrush complexes were weakly supported in both trees. Moreover, the haplotypes of the Naumann's and dusky thrushes and the red-throated and black-throated thrushes were mixed, and no monophyletic subclade was observed for any thrush. We found that when combined with the identification of morphological characteristics, the haplotypes of most individuals were correctly assigned to their corresponding species or Turdus complex. There were a few haplotypes from intermediate specimens mixed between the two Turdus complexes. Three haplotypes from Naumann's thrush and one haplotype from the dusky thrush were distributed in the clade of red-throated and black-throated thrush complexes. In contrast, three haplotypes from the black-throated thrush and four haplotypes from the red-throated thrush were located in the clade of Naumann's and dusky thrush complexes.

Based on the microsatellite dataset, a NJ tree was constructed based on SADs between individuals from the Naumann's and dusky thrush complexes and the red-throated and black-throated thrush complexes (Fig. 2). Although the test performance was worse when SADs were used (data not shown), and the bootstrap support values were relatively low, all individuals were divided into two groups, corresponding to two thrush complexes. Notably, each group was mixed with several individuals from other groups.

\subsection{Delimiting species}

Based on the average pairwise nucleotide distances calculated using the Kimura 2-parameter (K2P) model, the mean divergences of these two thrush complexes were $0.020 \pm 0.004$ for ND2 and $0.012 \pm 0.004$ for COI, which were significantly smaller than the genetic distances between each thrush complex and other thrushes, such as pale thrush ( T. pallidus ) (Table 4). The mean divergence between Naumann's thrush and the dusky thrush was $0.003 \pm 0.001$ for ND2 and $0.005 \pm 0.002$ for COI, which was similar to the genetic variations within Naumann's thrush or the dusky thrush. The mean divergence between the red-throated and black-throated thrushes was $0.07 \pm 0.002$ for ND2 and $0.001 \pm 0.001$ for COI, which was intermediate to or the same as the genetic variations in each thrush.

Based on ML and BI phylogenetic trees of two thrush complexes, we found that different combinations of priors (evolutionary scenarios: population size and divergence time) yielded different results by Bayesian species definition on each node, but the results of the analysis using algorithms 0 and 1 were similar (Table 5 ). This result indicated a convergence of MCMC chains. Combined with the guidance tree (Fig. 3), the results showed that nodes 3 and 4 had high speciation probabilities $=1.000$ when using combinations of priors that represent different evolutionary scenarios. At the same time, these two nodes of the guide tree were supported by high posterior probabilities (PPs $>95 \%$ ). For nodes 1 and 2, the choice of different evolutionary scenarios resulted in different speciation probabilities that were low in most cases. Therefore, the prior probability distribution had a greater influence on the speciation probabilities between Naumann's thrush and the dusky thrush and between the red-throated thrush and the black-throated thrush.

We used five morphological features to further analyze the classification status of the species in the two thrush complexes. The PCA showed that the five quantifiable traits were difficult to distinguish between Naumann's and the dusky thrush or the red-throated thrush and the black-throated thrush. These traits were not sufficient to constitute the boundary of the species (Fig. 4a and b). We classified the Naumann's and dusky thrush complexes as one group and the red-throated and black-throated thrush complexes as another group and conducted PCA of both groups (Fig. 4c). Although there was a small amount of intersection between the two groups, there was separation between them. All the results from the above molecular and morphological analyses indicated that the two thrush complexes should be two independent species (Naumann's thrush, T. naumanni, and the red-throated thrush, T. ruficollis), while the dusky thrush ( $T$. naumanni eunomus ) should be a northern subspecies of $T$. naumanni, and the black-throated thrush ( $T$. ruficollis atrogularis ) should be a black-throated subspecies of T. ruficollis .

\subsection{Genetic differentiation}

Due to the small sample size of the black-throated thrushes, we only calculated the genetic differentiation 
among the other three bird types. Based on mtDNA, the pairwise $F$ st value between Naumann's thrush and the dusky thrush was 0.051 , and the gene flow was high $\left(N_{e} m=4.68\right)$, while the pairwise $F$ st value between the two species T. naumanni and T. ruficollis was 0.773 or 0.798 , and the gene flow was extremely low $\left(N_{e} m\right.$ $=0.06$ and 0.07 , respectively) (Table 6a). All pairwise tests between species were significant $(P<0.05)$. The values of $F$ st and $N_{e} m$ between the two species suggested that they had significant genetic differentiation.

Based on microsatellite loci, the pairwise $F$ st value between Naumann's thrush and the dusky thrush was 0.012 , and the gene flow was very high $\left(N_{e} m=20.58\right)$, while the pairwise $F$ st value between the two species T. naumanni and T. ruficollis was 0.056 or 0.074 , and the gene flow was also high $\left(N_{e} m=4.21\right.$ and 3.12 , respectively) (Table 6b). All pairwise tests between species were significant $(P<0.05)$. The $F$ st and $N_{e} m$ values between the two species suggested that they had moderate genetic differentiation.

We performed Bayesian clustering with six microsatellite loci using STRUCTURE software (Fig. 5). Submitting the results to the Structure Harvester online software for the best K indicated that the population structure was clearest when K was equal to 4 (Fig S1). However, the STRUCTURE results showed no individual clustering in each bird taxon and no significant differentiation, indicating that the nuclear information of the four bird taxa was mixed.

\section{Discussion}

\subsection{Integrative taxonomy of two thrush complexes}

The classification of the Naumann's and dusky thrush complexes and the red-throated and black-throated thrush complexes is controversial (Kratter, 2014; Sibley, 1990). These thrushes have obvious morphological differences in color and feather striping (Table 2; (Brazil, 2009; Chang, 1995). The dusky thrush occupies habitats similar to those of Naumann's thrush but is generally found at higher latitudes and altitudes in summer (Brazil, 2009). The song of the dusky thrush is similar to that of Naumann's thrush, but the first phrase is more strongly emphasized (Brazil, 2009). The ranges of the black-throated and red-throated thrushes partially overlap in summer and winter. The songs of these two birds are also similar, but that of the red-throated thrush lacks the chattering quality. Herein, our PCA of quantifiable traits showed separation between the two thrush complexes but not within each complex (Fig. 4). Morphological differences in the colors and stripes of the feathers within each thrush complex could be adaptations to the subtle variation in the ecological factors of their habitats.

Our phylogenetic analysis based on mitochondrial genes indicated that all haplotypes could be divided into two reciprocally monophyletic sister clades corresponding to these two thrush complexes; the haplotypes of Naumann's thrush mixed with those of the dusky thrush, and the similar situations appeared in those of red-throated and black-throated thrushes (Fig. 1). Similar results have been suggested in other phylogenetic reconstructions of these two thrush complexes using mitochondrial genes and nuclear introns (Nylander et al., 2008), mitogenomes (Dong et al., 2018), and MHC class I exon 3 (Muhammad, 2021). Hennig (1966) articulated a method by which the evolutionary relationships of organisms (phylogeny) can be reconstructed, and this reconstruction is subsequently turned into a hierarchical classification. Following Hennig's theory, the recognition of two separate species, Naumann's thrush, T. naumanni, and the red-throated thrush, T. ruficollis, was supported. The dusky thrush ( T. naumanni eunomus ) should be a northern subspecies of $T$. naumanni, and the black-throated thrush (T. ruficollis atrogularis ) should be a black-throated subspecies of T. ruficollis . Moreover, the same results were revealed by coalescence-based species delimitation (Fig. 3 and Table 5). The above classifications were also supported by an analysis of genetic differentiation between T. naumanni and T. ruficollis and within each bird. In other words, based on mtDNA or microsatellite loci, intraspecies gene flow is markedly greater than interspecific gene flow. In general, interspecific variation should be 10 times greater than intraspecies variation when using DNA barcoding to identify species (Kerr et al., 2007; Ravankar et al., 2015). The ratio between T. naumanni and T. ruficollis (3-5, Tabe 4) was lower $10(10 \times$ rule). This might be related to the application of the $10 \times$ rule, as species identification in Aves cannot be addressed by unique criteria (Tavares and Baker, 2008).

\subsection{Introgression between T. naumanni and T. ruficollis}


The NJ tree (Fig. 2) and the cluster analysis (Fig. 5) based on microsatellite loci showed the same results, suggesting that there was significant mixing between T. naumanni and T. ruficollis . Interestingly, there was still more frequent gene flow between these two species despite there being significantly less than that between the subspecies of each bird (Table 6). Thus, we believed that this gene flow could be the result of introgression via hybridization between two birds. Reproductive isolation generally occurs among different species, and its extent gradually increases over time with genetic differentiation. Previous studies have shown that introgression via hybridization is associated with incomplete reproductive isolation between species with recent speciation (Barton and Hewitt, 1989; Brown et al., 2015; Gay et al., 2007). Based on (Nylander et al., 2008), differentiation between T. naumanni and T. ruficollisoccurred approximately 0.25 million years before present (Ma). This time could be too short for the species to form a perfect barrier to gene flow. Our results agree with those reported by (Brazil, 2009), in which complexes of T. naumanni and T. ruficollis were found in Japan and South Korea. Similar complexes of these two birds are also shown in Fig. 1. Since they have a large overlapping distribution around the world while breeding in summer, it is possible for these two closely related species to have sufficient opportunities for introgression via hybridization.

Relative to the weak genetic structure between species suggested by microsatellite loci, the phylogenetic analysis based on mitochondrial genes indicated that they were two reciprocally monophyletic sister clades (Fig. 1). Moreover, the level of gene flow between T. naumanni and T. ruficollis was much lower based on mitochondrial genes, and there was obvious genetic differentiation between them (Table 6). A discordant pattern emerged between the mitochondrial and microsatellite data, i.e., nuclear-mitochondrial discordance between the two birds. There could be several reasons for this finding. First, it might be due to the inconsistent evolutionary rates of the two markers. Because the differentiation time between T. naumanni and T. ruficollis was short (0.25 Ma, (Nylander et al., 2008)), they have not differentiated at most microsatellite loci, and gradual high-homogeneity mutations reduced the possibility of microsatellite alleles being monophyletic (Lu et al., 2001). Second, introgression between species might be the main cause of nuclear-mitochondrial discordance. The recent interspecies crossing between T. naumanni and T. ruficollis might have resulted in significant nuclear introgression. Although the introgression of mitochondrial genes is more common in nature (Aboim et al., 2010; Kinoshita et al., 2019; Mao et al., 2013), nuclear introgression is also present in birds. Nuclear introgression mainly relies on male-biased gene flow. Since females are the heterogametic sex in birds, hybridization between species reduces fertility and/or viability among females, according to Haldane's rule (Orr, 1997). On average, the reproductive (adult) phase of life is reduced by one quarter in female hybrids compared with females of the parental species (Neubauer et al., 2014), which limits maternal introgression, such as mtDNA introgression (Haldane, 1922). Thus, we could suppose that the gene flow between T. naumanni and T. ruficollis was mainly driven by backcrossing with male hybrids.

Alternatively, nuclear-mitochondrial discordance might also be related to the sex-biased dispersal pattern of birds. In general, the dispersal pattern of birds is female biased, and female individuals are more frequently dispersed to areas where males of the same species do not exist, which promotes hybridization between different species (Clarke et al., 1997; Greenwood, 1980; Wang et al., 2014). However, a small number of birds have opposite dispersal patterns (Dallimer et al., 2002; Li and Merila, 2010; Williams and Rabenold, 2005). T. naumanni and T. ruficollis might also experience male-biased dispersal, and we need to further evaluate this possibility using more effective methods.

In parallel, increasing global warming might cause breeding areas to further overlap, which would increase the possibility of interspecific hybridization and eventually lead to species amalgamation (Rieseberg and Carney, 1998). In addition, considering the high level of gene flow between T. naumanni and T. ruficollis , we speculate that as the introgression between them continues, genetic information will be exchanged, which might affect their morphological and genetic integrity and decrease their interspecific differences.

\section{Conclusions}

Our study used combined characteristics from morphological analysis and multilocus approaches to show that the Naumann's and dusky thrush complexes and the red-throated and black-throated thrush complexes in the Turdidae family should be divided into two separate species (T. naumanni and T. ruficollis ) and two 
subspecies. Importantly, we validated extensive nuclear introgression between T. naumanni and T. ruficollis for the first time. We also provided a potential explanation of the mechanism of gene introgression and nuclear-mitochondrial discordance between the two birds. However, a more-comprehensive collection of specimens of these birds in their breeding range is needed to clarify the relationship between gene introgression and speciation in these birds.

\section{Acknowledgments}

This study was funded by the Fundamental Research Funds for the Central Universities (grant no. 2572018BE04). We are grateful to Prof. Wei Zhang, Prof. Xu Yanchun, and Associate Prof. Suying Bai for their help collecting partial samples.

\section{Declaration of Competing Interest}

The authors declare that they have no known competing financial interests or personal relationships that could have appeared to influence the work reported in this paper.

\section{Author contributions}

All authors have read and agree to the published version of the manuscript. Conceptualization, B.L., S.L.H.; methodology and validation, B.Y.A., D.Y.Y., B.L., and S.L.H.; formal analysis, B.Y.A. and D.Y. Y.; writing - original draft preparation, B.Y.A.; writing - review and editing, B.L.; polishing this manuscript on English, T. A.; supervision, B.L.; project administration, B.L.; funding acquisition, B.L.

\section{Abbreviations}

BI Bayesian inference; BS Bootstrap; COI Cytochrome C oxidase I; SADs Shared allele distances; He Expected heterozygosity; Ho Observed heterozygosity; HWE Hardy-Weinberg equilibrium; K2P Kimura 2parameter; Ma Million years before present; MCMC Markov chain Monte Carlo; ML Maximum likelihood; mtDNA mitochondrial DNA; Na The number of alleles; ND2 NADH dehydrogenase 2; Ne The number of effective alleles; $\mathrm{N}_{\mathrm{e}} \mathrm{m}$ The gene flow index; MJ Median-joining algorithm; PCA Principal component analysis; PIC Polymorphism information content; PP Bayesian posterior probability

\section{Date Availability Statement}

Data are available. DNA sequences: Genbank accessions MT977415-MT977542. Microsatellite genotypes and morphometric data are accessible in the Dryad data repository (https://doi.org/10.5061/dryad.w9ghx3fqr)

\section{ORCID}

Boang An https://orcid.org/ 0000-0002-6541-260X

Bo Li https://orcid.org/ 0000-0001-6824-4907

\section{Reference}

Aboim, M. A., Mavarez, J., Bernatchez, L., \& Coelho, M. M. (2010). Introgressive hybridization between two Iberian endemic cyprinid fish: a comparison between two independent hybrid zones. Journal of Evolutionary Biology, 23(4), 817-828. https://doi.org/10.1111/j.1420-9101.2010.01953.x.

Barton, N. H., \& Hewitt, G. M. (1989). Adaptation, speciation and hybrid zones. Nature, 341(6242), 497-503. https://doi.org/10.1038/341497a0.

Bolnick, D. I., \& Near, T. J. (2005). Tempo of hybrid inviability in centrarchid fishes (Teleostei : Centrarchidae). Evolution,59(8), 1754-1767. https://doi.org/10.1111/j.0014-3820.2005.tb01824.x.

Brazil, M. A. (2009). Birds of East Asia. Princeton University Press.

Brown, R. M., Techow, N., Wood, A. G., \& Phillips, R. A. (2015). Hybridization and back-crossing in giant petrels (Macronectes giganteus and M. halli) at bird island, South Georgia, and a summary of hybridization in Seabirds. Plos One, 10(3), 14. https://doi.org/10.1371/journal.pone.0121688. 
Cerqueira, P. V., Santos, M. P. D., \& Aleixo, A. (2016). Phylogeography, inter-specific limits and diversification of Turdus ignobilis (Aves: Turdidae). Molecular Phylogenetics and Evolution, 97, 177-186. https://doi.org/10.1016/j.ympev.2016.01.005.

Chang, J. C., Katsura, C., Liu, B.W., \& Zhang, P (1995). A field guide to the birds of Northeast China. Harbin. Heilongjiang Science and Technology Press.

Clarke, A. L., Saether, B. E., \& Roskaft, E. (1997). Sex biases in avian dispersal: A reappraisal. Oikos, 79(3), 429-438. https://doi.org/10.2307/3546885.

Dai, C., Wang, W., \& Lei, F. (2013). Multilocus phylogeography (mitochondrial, autosomal and Zchromosomal loci) and genetic consequence of long-distance male dispersal in black-throated tits (Aegithalos concinnus). Heredity, 110(5), 457-465. https://doi.org/10.1038/hdy.2012.114.

Dallimer, M., Blackburn, C., Jones, P. J., \& Pemberton, J. M. (2002). Genetic evidence for male biased dispersal in the red-billed quelea Quelea quelea. Molecular Ecology, 11(3), 529-533. https://doi.org/10.1046/j.09621083.2001.01454.x.

Dong, Y. Q., Li, B., \& Zhou, L. Z. (2018). A new insight into the classification of dusky thrush complex: bearings on the phylogenetic relationships within the Turdidae. Mitochondrial DNA Part A,29(8), 1245-1252. https://doi.org/10.1080/24701394.2018.1439026.

Excoffier, L., \& Lischer, H. E. L. (2010). Arlequin suite ver 3.5: a new series of programs to perform population genetics analyses under Linux and Windows. Molecular Ecology Resources, 10(3),564-567. https://doi.org/10.1111/j.1755-0998.2010.02847.x.

Gay, L., Neubauer, G., Zagalska-Neubauer, M., Debain, C., Pons, J. M., David, P., \& Crochet, P. A. (2007). Molecular and morphological patterns of introgression between two large white-headed gull species in a zone of recent secondary contact. Molecular Ecology,16(15), 3215-3227. https://doi.org/10.1111/j.1365294X.2007.03363.x.

Grant, P. R., \& Grant, B. R. (1992). Hybridization of bird species.Science, 256(5054), 193-197. https://doi.org/10.1126/science.256.5054.193.

Greenwood, P. J. (1980). Mating systems, philopatry and Dispersal in birds and mammals. Animal Behaviour, 28(NOV), 1140-1162. https://doi.org/10.1016/s0003-3472(80)80103-5.

Guo, D. C., \& Milewicz, D. M. (2003). Methodology for using a universal primer to label amplified DNA segments for molecular analysis.Biotechnology Letters, 25(24), 2079-2083. https://doi.org/10.1023/B:BILE.0000007075.24434.5e.

Haines, M. L., Stuart-Fox, D., Sumner, J., Clemann, N., Chapple, D. G., \& Melville, J. (2017). A complex history of introgression and vicariance in a threatened montane skink (Pseudemoia cryodroma) across an Australian sky island system. Conservation Genetics,18(4), 939-950. https://doi.org/10.1007/s10592-0170945-7.

Haldane, J. B. S. (1922). Sex ratio and unisexual sterility in hybrid animals. Journal of Genetics, 12(2), 101-109. https://doi.org/10.1007/bf02983075.

Hanna, Z. R., Dumbacher, J. P., Bowie, R. C. K., Henderson, J. B., \& Wall, J. D. (2018). Whole-genome analysis of introgression between the spotted owl and barred owl (Strix occidentalis and Strix varia, respectively; Aves: Strigidae) in Western North America. G3-Genes Genomes Genetics, 8(12), 3945-3952. https://doi.org/10.1534/g3.118.200754.

Kalinowski, S. T. (2002). Evolutionary and statistical properties of three genetic distances. Molecular Ecology, 11(8),1263-1273. https://doi.org/10.1046/j.1365-294X.2002.01520.x.

Kalinowski, S. T., Taper, M. L., \& Marshall, T. C. (2007). Revising how the computer program CERVUS 
accommodates genotyping error increases success in paternity assignment. Molecular Ecology,16(5), 10991106. https://doi.org/10.1111/j.1365-294X.2007.03089.x.

Kerr, K. C. R., Birks, S. M., Kalyakin, M. V., Red'kin, Y. A., Koblik, E. A., \& Hebert, P. D. N. (2009). Filling the gap - COI barcode resolution in eastern Palearctic birds. Frontiers in Zoology,6, 29. https://doi.org/10.1186/1742-9994-6-29.

Kerr, K. C. R., Stoeckle, M. Y., Dove, C. J., Weigt, L. A., Francis, C. M., \& Hebert, P. D. N. (2007). Comprehensive DNA barcode coverage of North American birds. Molecular Ecology Notes, 7(4),535-543. https://doi.org/10.1111/j.1471-8286.2006.01670.x.

Kinoshita, G., Nunome, M., Kryukov, A. P., Kartavtseva, I. V., Han, S. H., Yamada, F., \& Suzuki, H. (2019). Contrasting phylogeographic histories between the continent and islands of East Asia: Massive mitochondrial introgression and long-term isolation of hares (Lagomorpha: Lepus). Molecular Phylogenetics and Evolution,136, 65-75. https://doi.org/10.1016/j.ympev.2019.04.003.

Kratter, A. W. (2014). The howard and moore complete checklist of the birds of the world. The Auk.

Leache, A. D., \& Reeder, T. W. (2002). Molecular systematics of the Eastern Fence Lizard (Sceloporus undulatus): A comparison of parsimony, likelihood, and Bayesian approaches. Systematic Biology,51(1), 4468. https://doi.org/10.1080/106351502753475871.

Li, M. H., \& Merila, J. (2010). Genetic evidence for male-biased dispersal in the Siberian jay (Perisoreus infaustus) based on autosomal and Z-chromosomal markers. Molecular Ecology, 19(23),5281-5295. https://doi.org/10.1111/j.1365-294X.2010.04870.x.

Lu, G., Basley, D. J., \& Bernatchez, L. (2001). Contrasting patterns of mitochondrial DNA and microsatellite introgressive hybridization between lineages of lake whitefish (Coregonus clupeaformis); relevance for speciation. Molecular Ecology, 10(4), 965-985. https://doi.org/10.1046/j.1365-294X.2001.01252.x.

Mallet, J. (2005). Hybridization as an invasion of the genome. Trends in Ecology \& Evolution, 20(5), 229-237. https://doi.org/10.1016/j.tree.2005.02.010.

Mao, X. G., He, G. M., Hua, P. Y., Jones, G., Zhang, S. Y., \& Rossiter, S. J. (2013). Historical introgression and the persistence of ghost alleles in the intermediate horseshoe bat (Rhinolophus affinis).Molecular Ecology, 22(4), 1035-1050. https://doi.org/10.1111/mec.12154.

Monroe B.L., Jr., \& Sibley C.G. (1993). A world checklist of birds. New Haven. Yale University Press.

Muhammad, U. G., Li B., An B., Xu Y., Shakeel H., \& Muhammad Y. (2021). Molecular characterization of MHC class I genes in four species of the Turdidae family to assess genetic diversity and selection. BioMed Research International, 2021, 14. https://doi.org/10.1155/2021/5585687.

Neubauer, G., Nowicki, P., \& Zagalska-Neubauer, M. (2014). Haldane's rule revisited: do hybrid females have a shorter lifespan? Survival of hybrids in a recent contact zone between two large gull species. Journal of Evolutionary Biology, 27(6), 1248-1255. https://doi.org/10.1111/jeb.12404.

Nguyen, L. T., Schmidt, H. A., von Haeseler, A., \& Minh, B. Q. (2015). IQ-TREE: A fast and effective stochastic algorithm for estimating maximum-likelihood phylogenies. Molecular Biology and Evolution,32(1), 268-274. https://doi.org/10.1093/molbev/msu300.

Nolte, A. W., \& Tautz, D. (2010). Understanding the onset of hybrid speciation. Trends in Genetics, 26(2),https://doi.org/54-58. 10.1016/j.tig.2009.12.001.

Nylander, J. A. A., Olsson, U., Alstrom, P., \& Sanmartin, I. (2008). Accounting for phylogenetic uncertainty in biogeography: A Bayesian approach to dispersal-vicariance analysis of the thrushes (Aves : Turdus). Systematic Biology, 57(2), 257-268. https://doi.org/10.1080/10635150802044003. 
Orr, H. A. (1997). Haldane's rule. Annual Review of Ecology and Systematics, 28, 195-218. https://doi.org/10.1146/annurev.ecolsys.28.1.195.

Petit, R. J., \& Excoffier, L. (2009). Gene flow and species delimitation. Trends in Ecology EJ Evolution, 24(7),386-393. https://doi.org/10.1016/j.tree.2009.02.011.

Pfennig, K. S. (2021). Biased hybridization and its impact on adaptive introgression. Trends in Ecology $\mathbb{E}$ Evolution, 36(6),488-497. https://doi.org/10.1016/j.tree.2021.02.010.

Phuong, M. A., Bi, K., \& Moritz, C. (2017). Range instability leads to cytonuclear discordance in a morphologically cryptic ground squirrel species complex. Molecular Ecology, 26(18), 4743-4755. https://doi.org/10.1111/mec.14238.

Pritchard, J. K., Stephens, M., \& Donnelly, P. (2000). Inference of population structure using multilocus genotype data. Genetics,155(2), 945-959. https://doi.org/10.1093/genetics/155.2.945

Randler, C. (2002). Avian hybridization, mixed pairing and female choice. Animal Behaviour, 63, 103-119. https://doi.org/10.1006/anbe.2001.1884.

Rannala, B., \& Yang, Z. H. (2003). Bayes estimation of species divergence times and ancestral population sizes using DNA sequences from multiple loci. Genetics, 164(4), 1645-1656. https://doi.org/10.1093/genetics/164.4.1645

Ravankar, A., Wagh, G. A., \& Wadatkar, J. S. (2015). DNA Barcoding and phylogenetic analysis of Tyto alba, Otus bakkamoena and Athene brama from Indian subcontinent. International Journal of Zoology and Research , 5(5).

Raymond, M., \& Rousset, F. (1995). GENEPOP (version-1.2) - population-genetics software for exact tests and ecumenicism. Journal of Heredity, 86(3), 248-249. https://doi.org/10.1093/oxfordjournals.jhered.a111573.

Rieseberg, L. H., \& Carney, S. E. (1998). Plant hybridization.New Phytologist, 140(4), 599-624. https://doi.org/10.1046/j.1469-8137.1998.00315.x.

Ronquist, F., \& Huelsenbeck, J. P. (2003). MrBayes 3: Bayesian phylogenetic inference under mixed models. Bioinformatics,19(12), 1572-1574. https://doi.org/10.1093/bioinformatics/btg180.

Rosenberg, N. A. (2003). The shapes of neutral gene genealogies in two species: Probabilities of monophyly, paraphyly, and polyphyly in a coalescent model. Evolution, 57(7), 1465-1477. https://doi.org/10.1554/03012.

Sangster, G., Collinson, J. M., Knox, A. G., Parkin, D. T., \& Svensson, L. (2007). Taxonomic recommendations for British birds: Fourth report.Ibis, 149(4), 853-857. https://doi.org/10.1111/j.1474-919X.2007.00758.x.

Schuelke, M. (2000). An economic method for the fluorescent labeling of PCR fragments. Nature Biotechnology, 18(2), 233-234. https://doi.org/10.1038/72708.

Seixas, F. A., Boursot, P., \& Melo-Ferreira, J. (2018). The genomic impact of historical hybridization with massive mitochondria DNA introgression. Genome Biology, 19, 20. https://doi.org/10.1186/s13059-018-14718.

Sibley, C. G., Monroe, B.L., \& Jr. (1990). Distribution and taxonomy of birds of the world. New Haven, Yale University Press.

Simeoni, M., Dawson, D. A., Gentle, L. K., Coiffait, L., Wolff, K., Evans, K. L., Gaston, K. J., \& Hatchwell, B. J. (2009). Characterization of 38 microsatellite loci in the European blackbird, Turdus merula (Turdidae, AVES). Molecular Ecology Resources,9(6), 1520-1526. https://doi.org/10.1111/j.1755-0998.2009.02708.x. 
Sorenson, M. D., Ast, J. C., Dimcheff, D. E., Yuri, T., \& Mindell, D. P. (1999). Primers for a PCR-based approach to mitochondrial genome sequencing in birds and other vertebrates. Molecular Phylogenetics and Evolution, 12(2), 105-114. https://doi.org/10.1006/mpev.1998.0602.

Takezaki, N., \& Nei, M. (1996). Genetic distances and reconstruction of phylogenetic trees from microsatellite DNA. Genetics,144(1), 389-399. https://doi.org/10.1093/genetics/144.1.389.

Tamura, K., Peterson, D., Peterson, N., Stecher, G., Nei, M. \& Kumar, S. (2011) MEGA5: Molecular evolutionary genetics analysis using maximum likelihood, evolutionary distance, and maximum parsimony methods. Molecular Biology and Evolution, 28(10), 2731-2739. https://doi.org/10.1093/molbev/msr121.

Tavares, E. S., \& Baker, A. J. (2008). Single mitochondrial gene barcodes reliably identify sister-species in diverse clades of birds.Bmc Evolutionary Biology, 8, 14. https://doi.org/10.1186/1471-2148-8-81.

Toews, D. P. L., \& Brelsford, A. (2012). The biogeography of mitochondrial and nuclear discordance in animals. Molecular Ecology, 21(16), 3907-3930. https://doi.org/10.1111/j.1365-294X.2012.05664.x.

Vigfusdottir, F., Palsson, S., \& Ingolfsson, A. (2008). Hybridization of glaucous gull (Larus hyperboreus) and herring gull (Larus argentatus) in Iceland: mitochondrial and microsatellite data. Philosophical Transactions of the Royal Society B-Biological Sciences,363(1505), 2851-2860. https://doi.org/10.1098/rstb.2008.0042.

Walsh, J., Shriver, W. G., Olsen, B. J., \& Kovach, A. I. (2016). Differential introgression and the maintenance of species boundaries in an advanced generation avian hybrid zone. Bmc Evolutionary Biology, 16, 18. https://doi.org/10.1186/s12862-016-0635-y.

Wang, W. J., Dai, C. Y., Alstrom, P., Zhang, C. L., Qu, Y. H., Li, S. H., Yang, X. J., Zhao, N., Song, G., \& Lei, F. M. (2014). Past hybridization between two East Asian long-tailed tits (Aegithalos bonvaloti and A. fuliginosus). Frontiers in Zoology, 11,13. https://doi.org/10.1186/1742-9994-11-40.

Weir, B. S., \& Cockerham, C. C. (1984). Estimating F-statistics for the analysis of population-structure Evolution, 38(6),1358-1370. https://doi.org/10.1111/j.1558-5646.1984.tb05657.x.

Williams, D. A., \& Rabenold, K. N. (2005). Male-biased dispersal, female philopatry, and routes to fitness in a social corvid.Journal of Animal Ecology, 74(1), 150-159. https://doi.org/10.1111/j.1365-2656.2004.00907.x.

Yang, Z. H., \& Rannala, B. (2010). Bayesian species delimitation using multilocus sequence data. Proceedings of the National Academy of Sciences of the United States of America, 107(20), 9264-9269. https://doi.org/10.1073/pnas.0913022107.

Zheng, G. M. (2017). A checklist on the classification and distribution of the birds of China. Beijing, Science Press.

Zheng, Z. X. (1994). A complete checklist of species and subspecies of the Chinese birds. Beijing, Science Press.

\section{Hosted file}

figure.docx available at https://authorea.com/users/447785/articles/546727-integrativetaxonomy-of-two-thrush-complexes-aves-turdidae-reveals-introgression-across-sisterspecies 